\title{
Modeling of Urban Growth Using Cellular Automata and GIS Case of Benslimane in Morocco
}

\author{
Mohamed Benchelha ${ }^{1}$, Fatiha Benzha ${ }^{1}$, Hassan Rhinane ${ }^{1}$, Said Benchelha ${ }^{2}$, Taoufik Benchelha ${ }^{2}$, \\ Najat Benchelha ${ }^{3}$ and Mohamed Bezza ${ }^{3}$ \\ 1 Geosciences Laboratory, Faculty of Science Ain Chock, Km 8 El Jadida Road, B.P 5366 Maarif Casablanca \\ 20100, Morocco; benchelha.doc@gmail.com (M.B.); benzhafatiha@yahoo.fr (F.B.); h.rhinane@gmail.com \\ (H.R.) \\ 2 Laboratory of geosciences applied to planning engineering, Faculty of Science Ain Chock, Km 8 El Jadida \\ Road, B.P 5366 Maarif Casablanca 20100, Morocco; said1.benchelha@gmail.com (S.B) ; \\ benya.taoufik@gmail.com (T.B) \\ 3 Atmospheric physics, Modeling and Materials Laboratory, Faculty of science and Technology of \\ Mohammedia, najat.benchelha@gmail.com (N.B.); mohamed.bezza@fstm.ac.ma (M.B) \\ * Correspondence: benchelha.doc@gmail.com
}

\begin{abstract}
In this study, our goal was to research land-use change by combining spatio-temporal land use/land cover monitoring (LULC (1989-2019) and urban growth modeling (1999-2039) in Benslimane, Morocco, to determine the effect of urban growth on different groups based on cellular automata (CA) and geospatial methods. A further goal was to test the reliability of the AC algorithm for urban expansion modeling. To do this, four years of satellite data were used at the same time as population density, downtown distance, slope, and ground road distance. The LULC satellite reported a rise of $3.8 \mathrm{~km}^{2}$ (318\% variation) during 1989-2019. Spatial transformation analysis reveals a good classification similarity ranging from $89 \%$ to $91 \%$ with the main component analysis (PCA) technique. The statistical accuracy between the satellite scale and the replicated built region of 2019 gave $97.23 \%$ t of the confusion matrix overall accuracy, and the region under the receiver operational characteristics (ROC) curve to 0.94, suggesting the model's high accuracy. Although the constructed area remains low relative to the total area of the municipality's territory, the LULC project shows that the urban area will extend to $5,044 \mathrm{~km}^{2}$ in 2019 , principally in the western and southwestern sections. In 2019-2039, urban development is expected to lead to a transformation of the other class (loss of $1,364 \mathrm{~km}^{2}$ ), followed by vegetation cover (loss of 0.345 $\mathrm{km}^{2}$ ). In spatial modeling and statistical calculations, the GDAL and NumPy Python 3.8 libraries were successful.
\end{abstract}

Keywords: Urban growth; cellular automata; Benslimane; GIS; Landsat

\section{Introduction}

Urbanization is a significant symbol of the growth of science, technology, and the greater capacity of humanity to reform the natural world. It is also one of the required measures to modernize a country [1]. In the local natural environment, the rapid development of urban areas has an impact on the complex socio-economic and natural systems, such as deforestation, air pollution, and agricultural land reduction [2,3]. To ensure sustainable urban growth [4] and to explicitly understand the spatial distribution of urban areas and spatio-temporal patterns, it is important to find an effective method to simulate and model urban expansion[5-7]. A variety of techniques and models have been developed over the last three decades to explain the dynamics of urban growth processes [8,9]. The introduction of the geographic information system (GIS) into the modeling of urban expansion was important at the end of the 20th century $[10,11]$, to understand the predictor 
variables of spatio-temporal changes. Regression models, including[12-16], artificial neural networks (RNA) [17-22], agent-based models (ABM) [23,24], are used for their efficient spatial computational capabilities. Cellular automata (CA) models are widely considered to be the most functional instruments [25-30],Tobler first suggested the urban AC model in 1970, to simulate Detroit's urban growth. In San Francisco, Clarke et al. [31] simulated shifts in land use using the SLUTH CA model. Batty and Xie [32], using the CA model, researched urban sprawl in Baffalo. To research the urban growth of Guangzhou, Wu [33] developed a logistic regression CA model. In northern China, He et al. [34] simulated land use shifts by integrating the model of system dynamics and the model of CA. The urban growth of Dongguan was simulated by Li and Gar-On Yeh [35], using data mining and AC. Li et al. [36] applied the GPU technique to the CA model to simulate improvements in urban land use in the province of Guangdong. Mustafa et al. [37] merged cellular automatons and agent-based approaches in Wallonia, Belgium, to model urban growth from 1990 to 2000 [38]. The urban planning of the cities of the Pearl River Delta was analyzed by Liu et al. [39] by combining the Landscape Expansion Index (LEI) and the CA model. In the last three decades, research using CA urban growth models have proliferated and provided in-depth insight into urban growth processes, which contributes to the development of strategic strategies for urban development to ensure a sustainable urban future [29]. The urban modeling and forecasting capabilities of CA models have been demonstrated and has been used successfully over the past fifteen years worldwide [40]. In this study, we aimed to examine the spatio-temporal dynamics of land use/land cover (LULC) over the past decades in order to model urban development for the municipality of Benslimane, Morocco using the CA algorithm. In this analysis, the LULC of four separate years: 1989, 1999, 2009, and 2019 was evaluated in order to achieve this objective. We also considered other criteria and growth parameters, such as topography, road proximity, proximity to the city center, demographic statistics, as well as areas with growth constraints. We estimated of the building scope for the future. The prediction of the future was useful in extrapolating the environmental effects of the urbanization of the town of Benslimane, which could help improve sustainability. In our analysis, we also report on the CA algorithm's accuracy and reliability in modeling the urban development of the city of Benslimane in Morocco. Benslimane is medium in size and in recent decades has undergone urban development and essential population influx. This development has contributed to a range of urban, environmental, and socio-economic issues, including the depletion of air quality, groundwater quality, temporary ponds, and green spaces. In recent decades, the urban area of Benslimane has expanded, so it seems appropriate to examine the urban growth trend and deduce its potential impact on other land use characteristics.

\section{Study Area}

The analysis was carried out on the territory of the town of Benslimane (Figure1), the capital of the agricultural province and hinterland, bordered to the west and north by the municipality of Ain Tizgha, to the south by the municipality of Ziaida, and to the east by the municipality of Oulad Yahya Louta. The high altitudes in the north-west range from 175 to around $390 \mathrm{~m}$ in the south-east. The area of the town of Benslimane is $72 \mathrm{~km}^{2}$, the polar coordinates are $33^{\circ} 36 \mathrm{~N}$ latitude and $7^{\circ} 06 \mathrm{~W}$ longitude, the average Lambert coordinates are $x=342,000, y=336,000$. The population of the town of Benslimane is approximately 58,000 Hah (RGPH 2014).

Figure 1. Map of the study area (Benslimane municipality). 

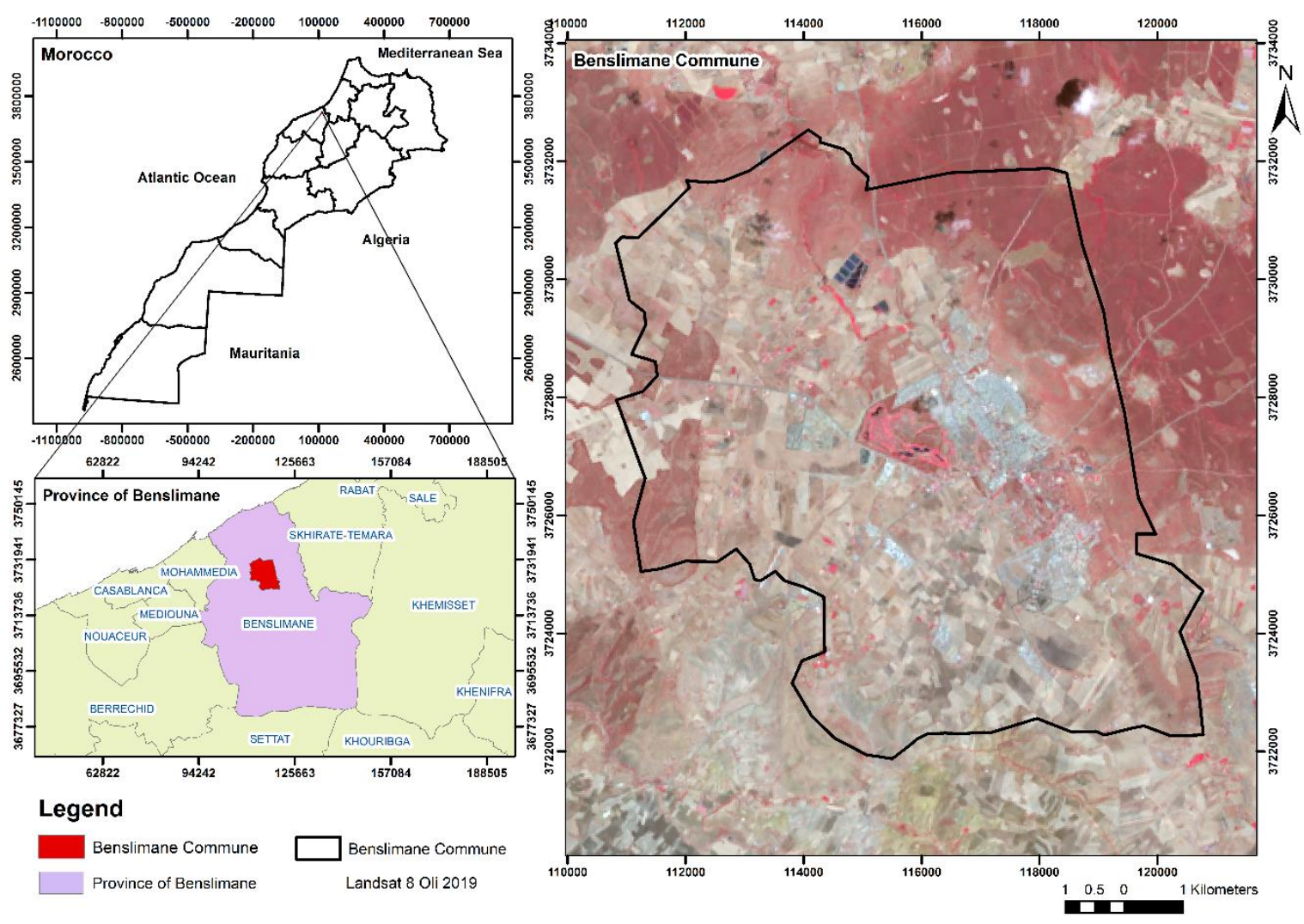

\subsection{Climate}

Benslimane has the following characteristics: a temperate and humid climate along the coastal regions. A dry climate with cold and heat alternating, with a continental climate when entering the mountainous regions and in the south of the province [41].

\subsection{Temperature}

Benslimane's annual average temperatures are $23.7^{\circ} \mathrm{C}$ for the maximum and $10.3{ }^{\circ} \mathrm{C}$ for the minimum. As one travels away from the Atlantic coast, there are considerable variations. The average annual temperature of the coastal zone is $17.5^{\circ} \mathrm{C}$, with a mean temperature not exceeding 32 ${ }^{\circ} \mathrm{C}$. The low interior plateaus show very high thermal amplitudes, but without sudden variations. The average annual temperature on these plateaus is $18.5^{\circ} \mathrm{C}$, with a high of $40^{\circ} \mathrm{C}$. [41].

\subsection{Rainfall}

The average annual rainfall recorded in the province is $350 \mathrm{~mm}$. The average annual precipitation measured for the period 1977-2008 for the Feddan Taba and Malleh Dam pluviometry stations is approximately $310 \mathrm{~mm}$. The average monthly distribution of rainfall suggests the presence of two distinct seasons: the wet season from October to May, during which nearly all rainy episodes occurred (86 to $92 \%$ of the annual rainfall); the dry season from May to September, with just 8 to $14 \%$ of the annual rainfall [41].

\section{Methods and Data Used}

This research involved numerous thematic layers prepared using satellite images, Benslimane census data, and topographic sheets. Land use/land cover maps (LULC) were prepared to consider the dynamics of urban development from 1989 to 2019 using satellite datasets. Different factors favoring urban growth with LULC were prepared as raster layers for modeling purposes, namely population density, slope, proximity to road networks, and proximity to the city center (Figure2). A model was carefully tuned to keep the simulated LULC both statistically and spatially similar to the 
real LULC to achieve the best possible threshold values. For a development forecast for the year 2029, the pattern of the threshold values obtained was evaluated. In ArcGIS, the LULC, roads; other thematic layers were processed in Python 3.8.

\subsection{Thematic layers}

LANDSAT multi-temporal satellite images for the years 1989, 1999, 2009, and 2019 were downloaded from the USGS website (https:/earthexplorer.usgs.gov) and were used to prepare LULC maps, using the classification to obtain various groups-constructed, vegetation, water area, and others. Tables 1 and 2 present a summary of the satellite data used and of the major LULC groups. The goal of this research was to design the built feature class, which includes constructed areas such as residential areas, companies, institutions, and informal settlements. Land was classified as vegetation primarily if it was under any form of green cover. Streams, etc., were included in the water zones, and the remainder was listed as other, mainly agricultural land. Satellite maps classified by the LULC were validated using field checks and Google Earth photos. For each of the observation years $(1989,1999,2009$, and 2019), the average accuracy was measured and ranged from 80 percent to 89 percent, while the kappa coefficient ranged from 0.73 to 0.85 . To examine LULC transition and urban sprawl over 1989-2019, and then to calibrate the model, the finalized LUC maps were adopted. To calculate the population density for 2024 and 2030 using the unit process, the thematic layers of population density by region were prepared. Demographic data from the Moroccan census (1994, 2004, and 2014) were taken into consideration for the simulations. During the model calibration method, population density maps for 1994, 2004, and 2014 were used and, for future forecast purposes, the population density map for 2024-2030 was used. To fit the geometry of the other participating layers, the density was determined in the vector layer attribute of the different areas of Benslimane, which was later converted to a raster layer of cell size $30 \times 30 \mathrm{~m}$. In all three groups $(<3,3-5,>5)$, the digital elevation model (DEM) with a spatial resolution of $30 \mathrm{~m}$ was used to prepare slope maps.

Figure 2. Procedures adopted in the study. 


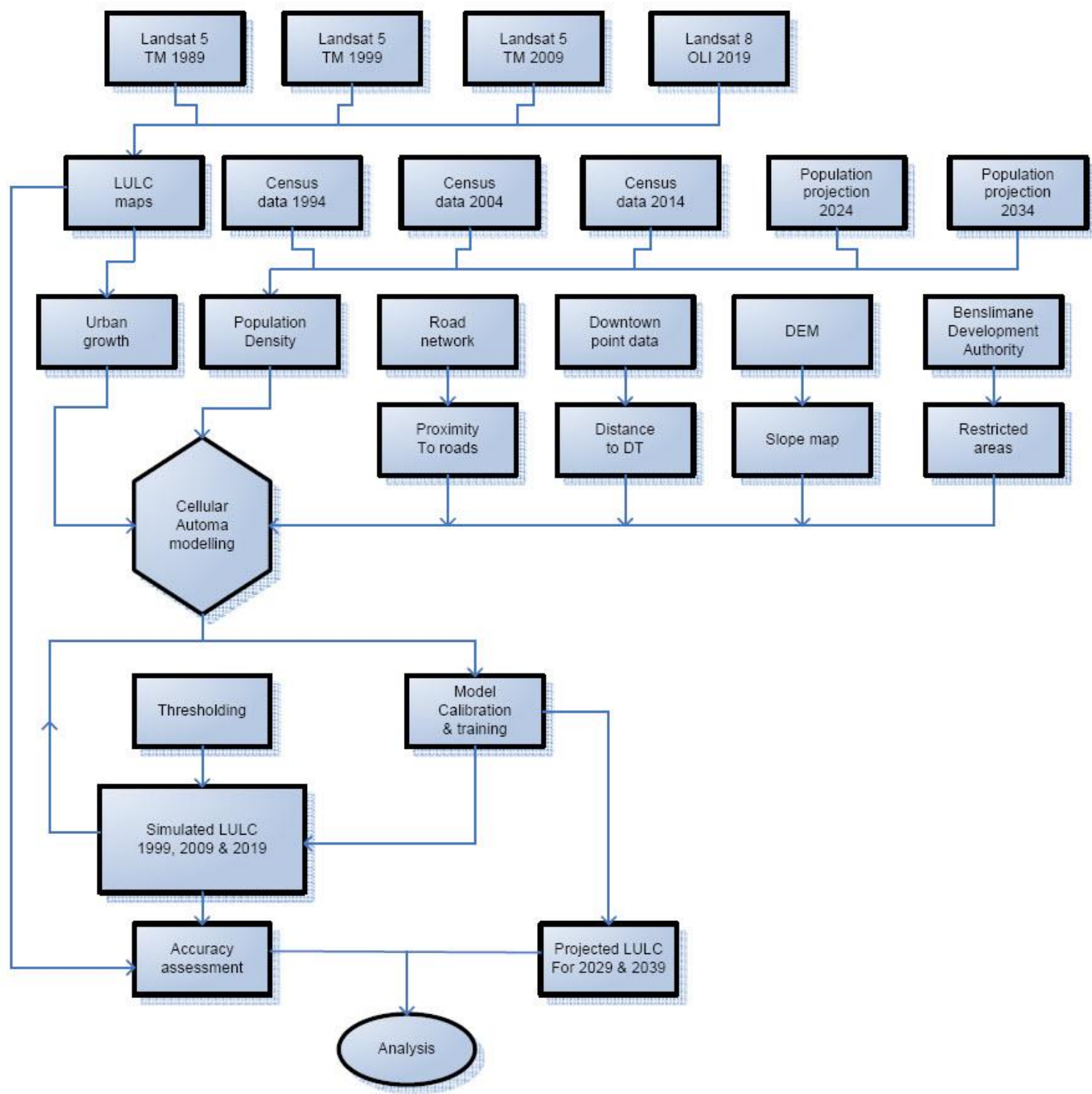

Table 1. Details of input data used in the study.

\begin{tabular}{lll}
\hline Data type & Details & Date of acquisition \\
\hline LANDSAT 5 TM & Path : $202 ;$ Row $: 37$ & $1989 / 08 / 07$ \\
LANDSAT 5 TM & Path : $202 ;$ Row $: 37$ & $1999 / 07 / 02$ \\
LANDSAT 5 TM & Path : $202 ;$ Row $: 37$ & $2009 / 06 / 27$ \\
LANDSAT 8 OLI & Path : 202 ; Row : 37 & $2019 / 06 / 23$ \\
& ASTER Global Digital Elevation & \\
Digital Elevation Model & Model V003 (spatial resolution & $2000-03-01$ \\
& $30 \mathrm{~m}$ ) & \\
General Population and Housing & high commission for morocco & $1994,2004,2014,2024$ \\
Census & plans & and 2030
\end{tabular}

Table 2. Characteristics of land use/land cover maps (LULC) feature class. 


\begin{tabular}{|c|c|c|}
\hline Feature class & characteristics & Description \\
\hline \multirow[t]{3}{*}{ Built-up } & Consist of & $\begin{array}{l}\text { All man-made structures that are primarily impervious including } \\
\text { residential areas, commercial areas, with low economic relevance }\end{array}$ \\
\hline & proximity & Parks, plantations, lakes, ponds, transport networks \\
\hline & significance & high to moderate population density \\
\hline \multirow[t]{3}{*}{ Végétation } & Consist of & $\begin{array}{l}\text { All green spaces and forests in the urban area and its surroundings, } \\
\text { including agricultural land, parks, plantations, protected forests, } \\
\text { agriculture }\end{array}$ \\
\hline & proximity & Moderate to low built-up structures and water bodies \\
\hline & significance & Public, private and government preserved area \\
\hline \multirow[t]{3}{*}{ Water } & Consist of & All water bodies \\
\hline & proximity & Low/high vegetation, open land \\
\hline & significance & Potable/non-potable water, contaminated, irrigational \\
\hline \multirow[t]{3}{*}{ Other } & Consist of & $\begin{array}{l}\text { Toutes les caractéristiques à l'exclusion des constructions, de la végétation } \\
\text { et de l'eau }\end{array}$ \\
\hline & proximity & Low / high vegetation, built structures \\
\hline & significance & Belonging to the private domain of the state and or to individuals \\
\hline
\end{tabular}

The main road network was obtained from the satellite picture showing proximity to the main roads, grading from $250 \mathrm{~m}$ to $3 \mathrm{~km}$ intervals. Similarly, in 8 classrooms, multiple buffer circles across the city center location were sampled at $1 \mathrm{~km}$ intervals. The vector layers were rasterized to a cell size of $30 \mathrm{~m}$ and cut to match the geometry of the old layers with a constant magnitude. A layer for restriction zones was considered to enhance the model's ability to replicate the current growth system. The model did not produce pixels accumulated in restricted areas representing the forest and habous lands by this binary layer.

\subsection{Model Algorithm for $C A$}

To take into account all the variables that lead to urban growth in Benslimane, the script for the CA model was formulated. A kernel of $3^{*} 3$ size kept the test pixel in its middle, as shown in Equation (i)

$$
A_{i j}^{t}=\left[\begin{array}{ccc}
a_{i-1 j-1}^{(t)} & a_{i-1 j}^{(t)} & a_{i-1 j i+1}^{(t)} \\
a_{i j-1}^{(t)} & a_{i j}^{(t)} & a_{i j+1}^{(t)} \\
a_{i+1 j-1}^{(t)} & a_{i+1 j}^{(t)} & a_{i+1 j+1}^{(t)}
\end{array}\right] 3^{(t)} 3 \text { neighbourhood }
$$

The model depends primarily on the current state of the test pixel, the current state of the immediately adjacent pixels, and the set of rules for transformation [42]. Matching layer geometry is important to ensure that in all raster layers, every random pixel (ai, j) represents the same piece of ground. According to the following equation [42], the dependence of the future state $(t+1)$ of a pixel on the passage rules (Ø) and the normal state of a pixel was examined:

$$
a_{i, j}^{t+1}=\emptyset\left(a_{i, j}^{t}\right)
$$
by:

The passing rules $(\varphi)$ were a function of a set of threshold conditional statements represented

$$
\emptyset=f(T, B)
$$

Equation (iii) suggests that the transition rules are a function of $\mathrm{T}$, a set of threshold values for all the affected parameters, and $\mathrm{B}$, a set of kernel count values associated with each set of $\mathrm{T}$.

$$
\begin{aligned}
& \mathrm{T}=\left\{T_{R}, T_{C}, T_{p}, T_{S}\right\} \\
& \mathrm{T}=\left\{B_{R}, B_{C}, B_{p}, B_{S}\right\}
\end{aligned}
$$


where the threshold values for road proximity, city center distance, population density, and slope value are TR, TC, TP, and TS, respectively; BR, BC, BP, and BS are the corresponding number of pixels incorporated in the test kernel for each element belonging to T. The laws of the adopted CA model comply with the existing general conditions in the real world: (a) Built-up land and water area classes were exempt from removal; (b) vegetation land or other classes can, depending on the threshold values (T) and the number of neighboring built-up pixels (B), move to built-up land if the test pixel falls into the unregulated area layer category [43].

\subsection{Calibrating the Model}

Using the LULC satellite data for 1989 to simulate the year 1999, the model calibration was adopted, then the LULC satellite data for 1999 was used to simulate the year 2009, and finally, the LULC satellite data for 2009 was used to simulate the year 2019. By simulating the LULC of time t2 using the LULC of time $\mathrm{t} 1$ and the driving parameters, the model deduced the best-defined threshold values, which represent the closest result to the real world [42], both statistically and spatially. The threshold values of the four factors (TR, TC, TP, and TS) and their corresponding integrated pixel count values (BR, BC, BP, and BS) were obtained through trial and error. Moreover, the script also tracked the contribution of each factor influencing the new integrated pixel generation. Threshold values were plotted after calibration, and trend lines were used to project thresholds for the future stage to estimate the extent of future accumulation [43].

Principal component analysis (PCA) was used to determine accuracy at each point of the simulation [43], where the difference between two images was determined by spatially subtracting the cumulative time pixels $\mathrm{t} 2$ from the corresponding time pixels $\mathrm{t} 1$. Here, from satellite and simulated LULC images from the same time, dichotomous made up layers were extracted. In the event of a change, the built-up area common to the two images was eliminated by subtraction and generated non-zero values $(1$ or -1$)$. For a precise percentage measure, the proportion of these non-zero values relative to the total number of pixels accumulated from satellite images was considered.

\section{Results and Discussion}

To deduce land use/land cover shift and urban sprawl patterns in Benslimane for 1989-2019, LULC satellite maps were prepared and analyzed. Later, to calibrate the model and predict the potential scale of the agglomeration, the key factors leading to urban growth were analyzed. To provide the best possible outcomes, care was taken to calibrate the model.

\subsection{Mapping and Urban Development of Land Use/Land Cover}

For 1989-2019, multi-temporal satellite data were used to chart land use/land cover at 10 year intervals. The real (satellite) LULC was named after this. The data was then used for 1999-2039 to simulate the LULC - the simulated LULC. During the model calibration period (for 1999-2019), these simulations were correlated with the satellite LULC.

\section{Satellite-Based Land Use/Land Cover Mapping and Urban Growth}

We found that the real built-up land (by satellite) increased from 1,206 to 5,044 $\mathrm{km}^{2}$ in 1989-2019 with a 5,305\% variation. Periodic observations show that the built-up region in 1989 was $1,206 \mathrm{~km}^{2}\left(1,667 \%\right.$ of the total area), which rose to $2,147 \mathrm{~km}^{2}(2,969 \%)$ in 1999 with a rise of $1,301 \%$ (Table 3). It increased to $2,999 \mathrm{~km}^{2}(4,146 \%)$ in 2009 with an 1,177\% rise. In 2019, the built-up area increased to $5,044 \mathrm{~km}^{2}(6,972 \%)$ with a $2,827 \%$ growth. The overall variation in the vegetation region was observed at 6,464\% between 1989 and 2019. In 1989, the vegetation cover covered 21,392 $\mathrm{km}^{2}$ (29.57\%) with a variation of $9,601 \%$, which increased to $28,337 \mathrm{~km}^{2}(39.17 \%)(1999)$. It then increased in 2009 to $31,223 \mathrm{~km}^{2}(43.16 \%)$ with a $3.989 \%$ variance. In 2019 , with a variation of $-7.127 \%$, the vegetation cover decreased to $26,068 \mathrm{~km}^{2}(36.04 \%)$. 
Table 3. During 1989-2019, the LULC region statistics (satellite-based vs. simulated).

\begin{tabular}{|c|c|c|c|c|c|c|c|c|c|c|c|c|c|}
\hline & \multirow{2}{*}{ Type } & \multicolumn{3}{|c|}{ Built-up land } & \multicolumn{3}{|c|}{ Vegetation cover } & \multicolumn{3}{|c|}{ Water body } & \multicolumn{3}{|c|}{ Others } \\
\hline & & Area $\left(\mathrm{km}^{2}\right)$ & $\%$ & $\Delta \%$ & Area $\left(\mathrm{km}^{2}\right)$ & $\%$ & $\Delta \%$ & Area $\left(\mathrm{km}^{2}\right)$ & $\%$ & $\Delta \%$ & Area $\left(\mathrm{km}^{2}\right)$ & $\%$ & $\Delta \%$ \\
\hline 1989 & Actual & 1.206 & 1.667 & - & 21.392 & 29.57 & - & 0.077 & 0.106 & - & 49.66 & 68.65 & - \\
\hline & Simulated & 2.330 & 3.221 & 1.554 & 28.104 & 38.85 & 9.278 & 0.255 & 0.352 & 0.246 & 41.67 & 57.61 & -11.043 \\
\hline 2009 & Actual & 2.999 & 4.146 & 1.177 & 31.223 & 43.16 & 3.989 & 0.313 & 0.433 & 0.066 & 37.80 & 52.26 & -5.232 \\
\hline 2019 & Simulated & 5.533 & 7.649 & 3.096 & 25.870 & 35.76 & -6.824 & 0.195 & 0.270 & -0.148 & 40.78 & 56.37 & 3.884 \\
\hline \multirow[t]{2}{*}{ 1989-2019 } & Actual & - & - & 5.305 & - & - & 6.464 & - & - & 0.173 & - & - & -11.942 \\
\hline & Simulated & - & - & 5.982 & - & - & 6.190 & - & - & 0.164 & - & - & -12.284 \\
\hline
\end{tabular}

In the class of water characteristics from 1989 to 2019, the cumulative variation observed was $0.173 \%$. In 1989 , the area protected by the water zones was $0.077 \mathrm{~km}^{2}(0.106 \%)$, which rose to 0.266 $\mathrm{km}^{2}(0.367 \%)$ with a $0.261 \%$ variation in 1999 . This area increased to $0.313 \mathrm{~km}^{2}(0.433 \%)$ in 2009 with a $0.066 \%$ variation. In 2019 , with a variation of $-0.154 \%$, the total area under the water zones rose to $0.202 \mathrm{~km}^{2}(0.279 \%)$. In the other function grades, the average decrease was $-11,942 \%$. In 1989 , all the remaining objects classified as others occupied a total area of $49.66 \mathrm{~km}^{2}(68.65 \%)$, which dropped to $41.59 \mathrm{~km}^{2}(57.49 \%)$ in 1999 with a $-11.164 \%$ improvement. In 2009 , with a difference of $-5,232 \%$, the area of the other class decreased to $37.80 \mathrm{~km}^{2}(52.26 \%)$, then to $41.02 \mathrm{~km}^{2}(56.71 \%)$ in 2019 with a difference of $4.454 \%$.

Our research illustrates the impact of urban sprawl from 1989 to 2019 on other LULC groups. Spatio-temporal mapping of LULC demonstrates that built-up land was largely concentrated in the central Benslimane area. Later, because of the availability of suitable sites and the advancement of the new development plan, the building was expanded to the south and southwest, resulting in a population increase. Since built-up areas determine the basic human-environment dynamics in urban environments, unbuilt elements (i.e., vegetation, water areas) are intrinsic components of built-up areas.

\subsection{Urban Expansion Modelling}

Urban growth modeling was carried out using an earlier LULC map and various contributing factors, close to major roads, city center, population density, and slope data, to forecast the future urban growth model for the year 2039.

\subsubsection{Contributing Factor in Urban Development}

The study indicates that the densification of the agglomeration and the formation of subdivisions in remote areas resulted from an irregular mixture of the impact of the road, the town center, and geomorphic parameters. The following sections discuss the different contributing parameters

\section{Land Use/Land Cover}

The probability of transformation of the various groups of LULC into built-up land is different. To this end, the group of others was given a higher rank, followed by vegetation. In modeling, constructed-up land was considered to be a non-transformable class.

\section{Proximity to Major Roads}

The road map shows the density of roads in the middle and south of the city, and the density in the northwest and southwest is lower. The density of roads in most suburban areas is poor (Figure 4a). Given the role of main roads in the urbanization process, the high accessibility of areas closer to roads has given growth priority and vice versa. 
As a major multi-urban functional area, the city center functions. To track non-uniform development in all directions, proximity to roads and the center was taken into account. Distance from the center has primarily affected urban growth in the central region, and as distance rises, its impact has diminished.

Figure 3. LANDSAT satellite images (a to c) (obtained from USGS), satellite-based LULC maps (d to f) and simulated LULC map (g to i) of Benslimane for the year 1999 (a, d, g), 2009 (b, e, h), and 2019 (c, f, i).

气ี้

(a)
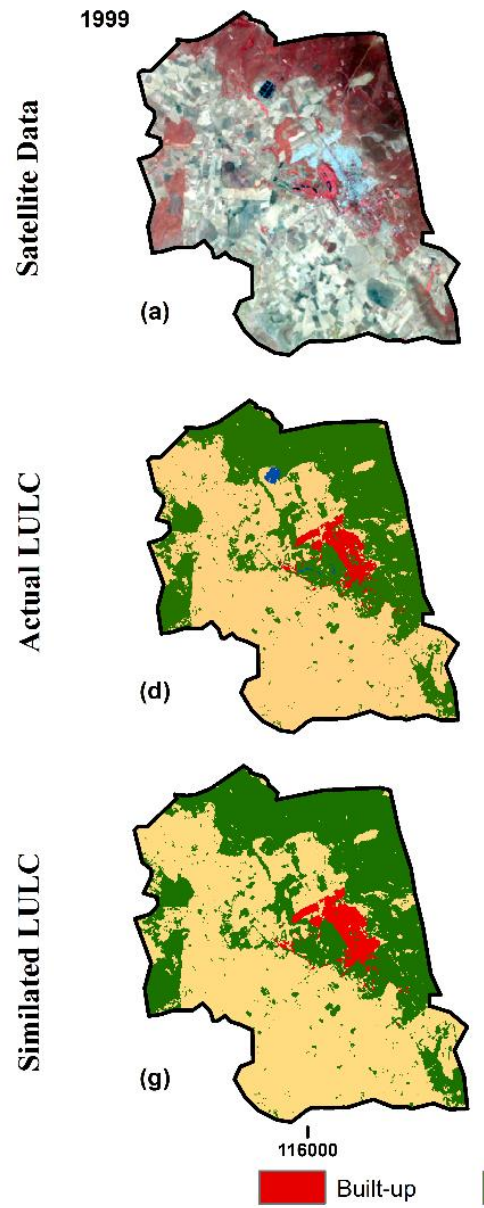

2009

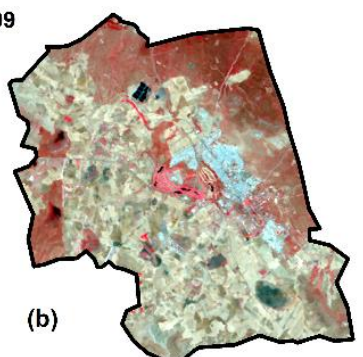

(e)

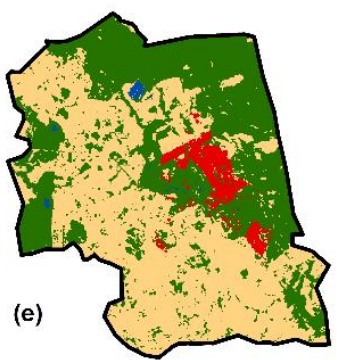

(h)

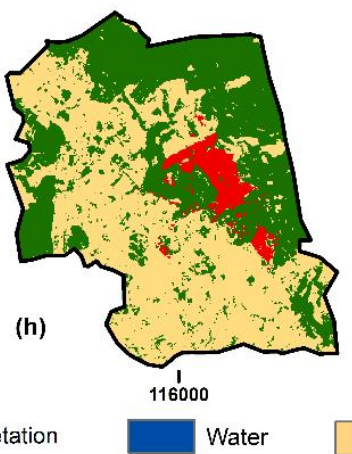

2019

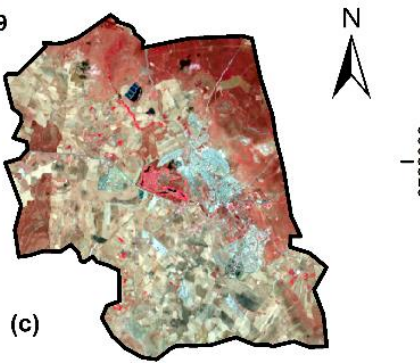

(f)
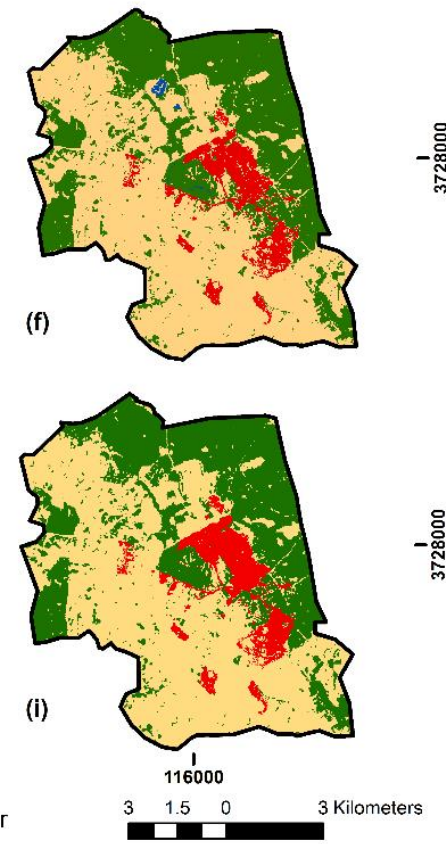

Slope

The analysis indicates that the relief ranges between 177 and 339 m relative to the Benslimane mean sea level (NGM). The Benslimane slope map shows that most of the region has a slope of less than $5^{\circ}$, but small parts have slopes greater than $5^{\circ}$ to the north, middle, southeast, and southwest (Figure 4 (c)). The slope of the land is a factor that has considerable influence over the growth of buildings. High landforms and steep slopes cause greater runoff and make the land less suitable for construction, whereas low landforms and gentle slopes provide buildings with a comparatively more stable foundation. This could explain why the growth of low slope areas was favored. 
Figure 4. Urban growth contributing factors (a) proximity to major roads, (b) proximity to downtown, (c) digital elevation model (DEM) based slope map, (d) restricted areas, and (e) temporal satellite-based LULC classified images of 1989-2019 of Benslimane.
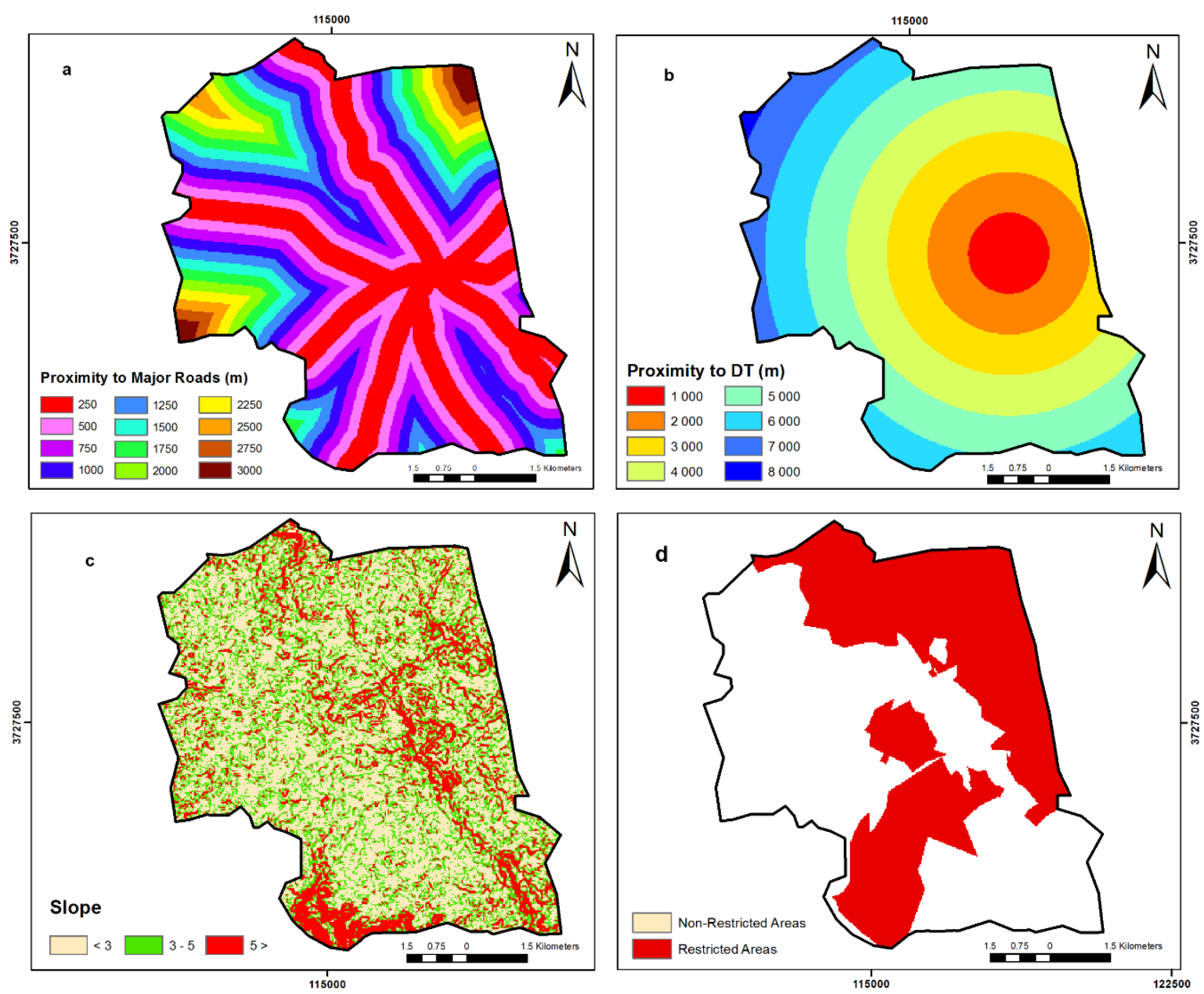

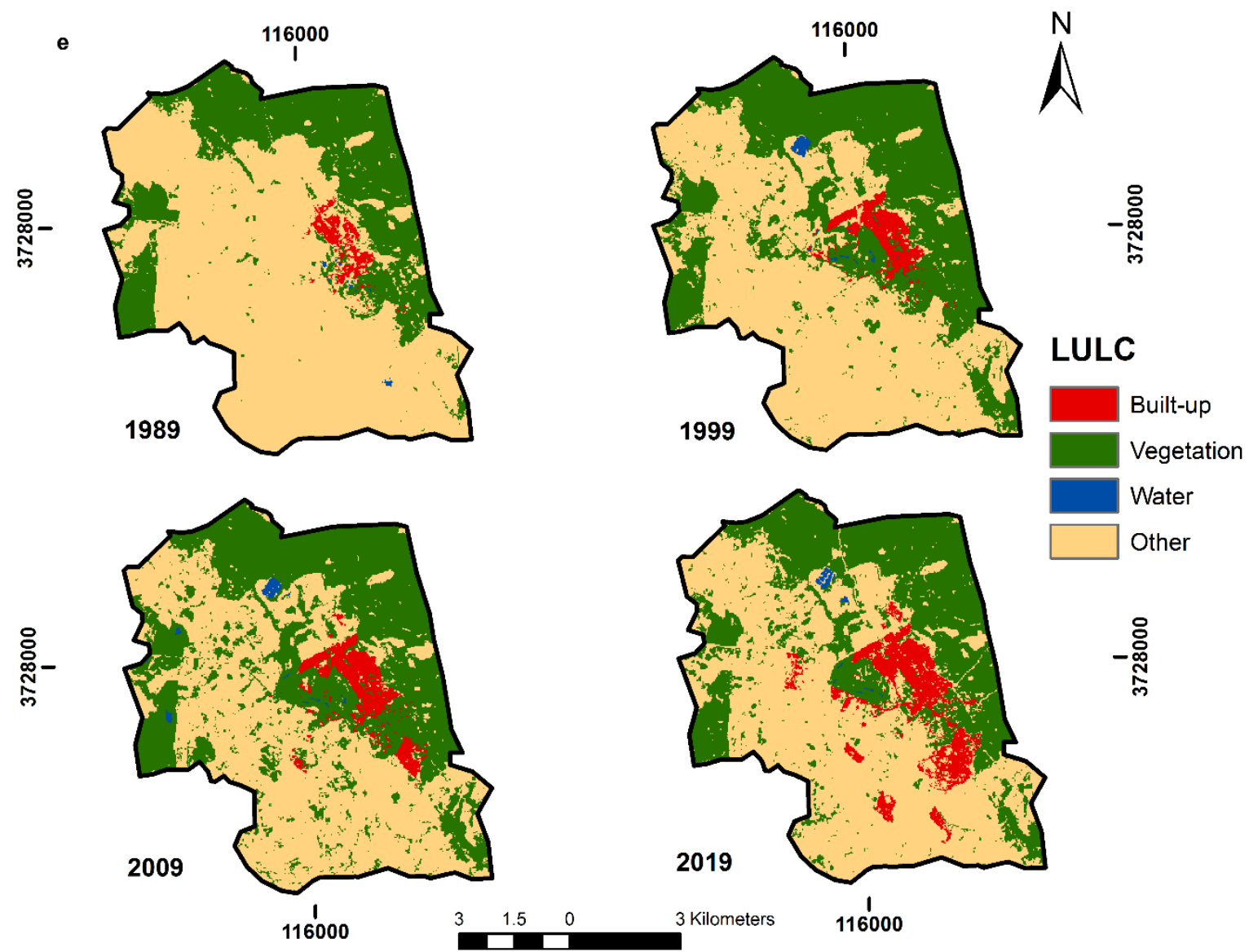

Population Density

In the early stages (1994-2014), in the middle of the city and a moderate rise in the south and southeast, the population density map at Benslimane indicates a greater increase in density. The population density in the central area has remained at $>15,000$ per $\mathrm{km}^{2}$ in the high-density class (Figure 5). In 1994 and 2004, population density changes were observed in the central-western areas. This may be the result of a transition brought on in Benslimane by a population influx and shifts in demographic policy. Population density maps (2030) prepared by the High Commission for Planning of Morocco's demographic prediction indicate a rise in population density in the center-north, center-west, and south-east, highlighting the future of Benslimane's expansion. There was no substantial change in population density between 2014 and 2030 in the Southwest. 
Figure5 . Urban Population density maps of Benslimane for different periods ,(a)1994),(b)2004,(c)2014,(d)2020 and (e) 2030
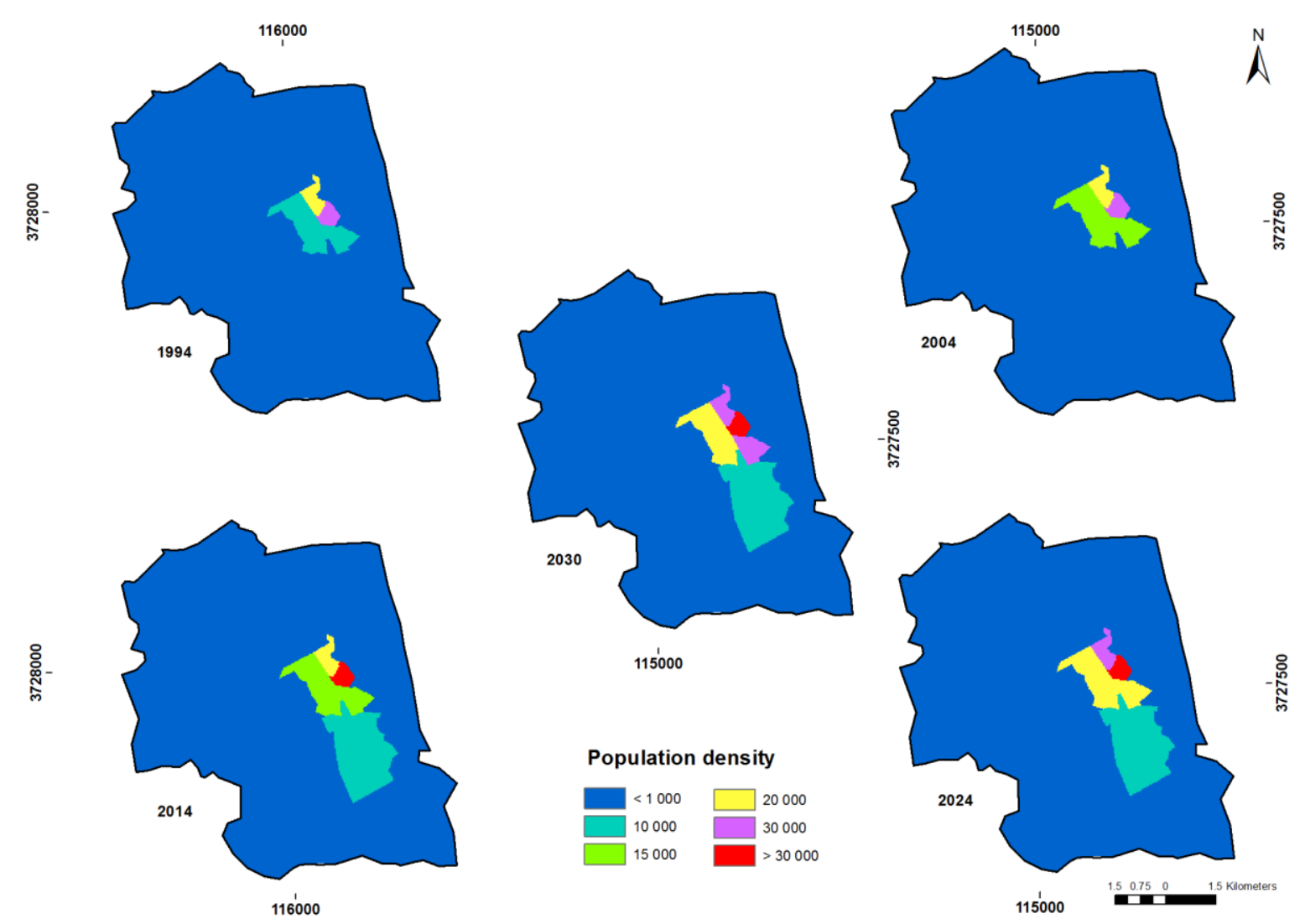

\subsubsection{Urban growth modeling using CA}

As shown in Figure 6, the simulated construction for different years was analogous to the real construction (by satellite). Built-up land is projected to increase from 5,044 km2 in 2019 to 6,092 km2 in 2029 (20,789 \% built growth), mostly in the city's west and south, and to 6,753 km2 in 2039 (10,844 $\%$ built growth), with city core densification and scattered development predominantly in the western and southwestern sections. The coverage of vegetation will grow from 26,068 km2 in 2019 to 25,889 km2 in 2029 (-0.684\% variation) and 25,723 km2 in 2039 (-0.643\% variation). It is expected that the area of the 'other' group will deteriorate, falling from 41,023 km2 in 2019 to 40,154 km2 in 2029 and finally to 39,659 km2 in 2039 (Figure 7). 
Figure 6. Graph showing the current (a) and simulated modification ( b) of LULC

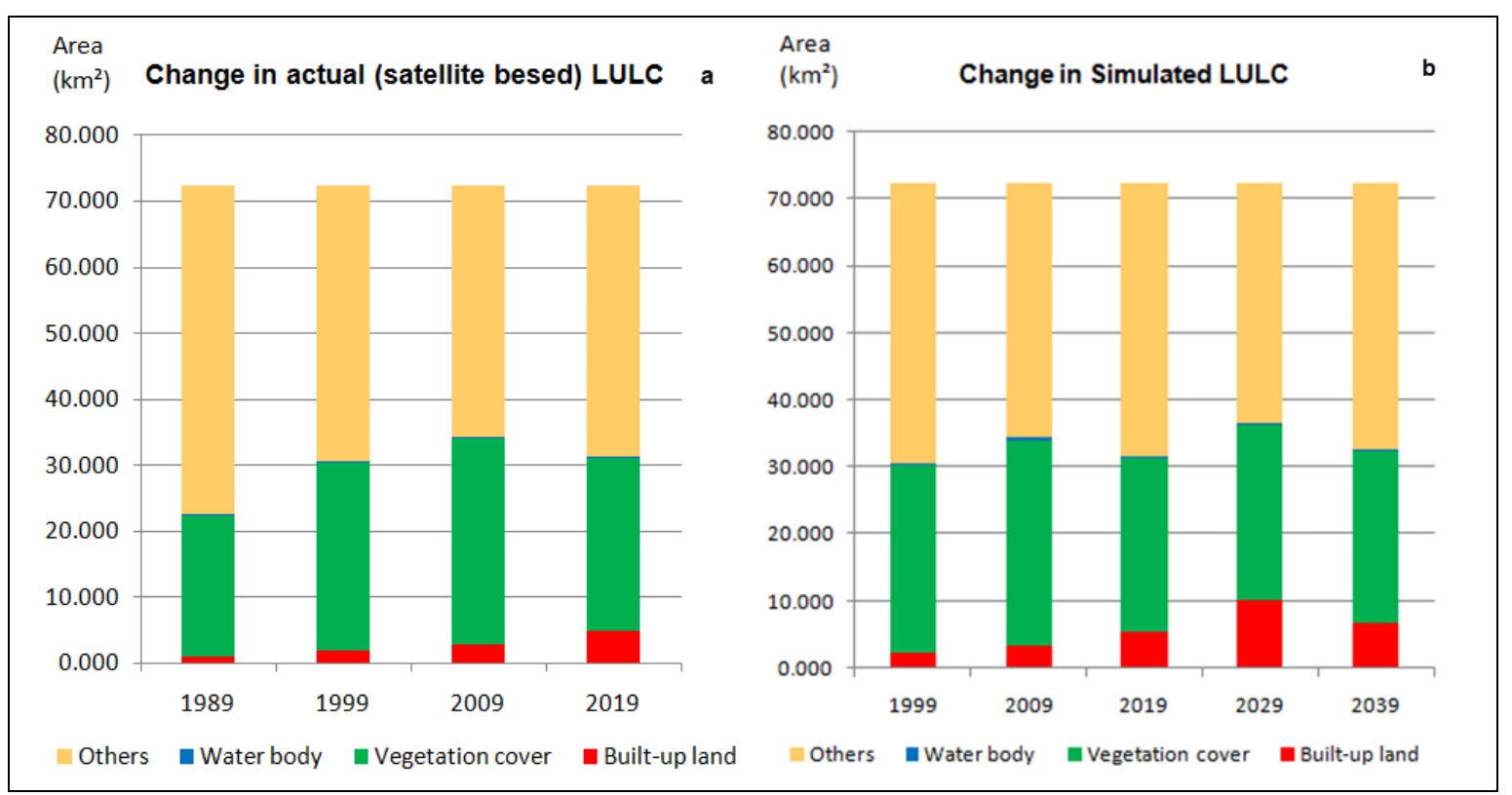

\subsubsection{Validation of the LULC simulated}

An accuracy assessment revealed a very high statistical and spatial similarity (> 89\%) between the simulated LULC and the satellite LULC for the known years (1999-2019), as shown in Table 4. The percentage of spatial accuracy and statistic was calculated with respect to the spatial location and built extent of built-up land in satellite LULCs. The calculated confusion matrix has an overall accuracy of 97,23\% (Table 6), and the area under the curve (AUC) of the receiver operating characteristics (ROC) graph (Figure 8) has been shown to be as high 0,94. The high precision of the confusion matrix and the AUC indicates high precision of the modeling. This is probably due to the use of an average prediction period (10 years) at regular intervals during the calibration as well as the proportion of the frame which represents only $7 \%$ of the overall area. The transition probability matrix was calculated using temporal land use / land cover maps (Tables 7 and 8) which show the transformation of pixels belonging to the four feature classes over a given period (1989 to 2019 and 2019 to 2039). The transition from 1989 to 2019 shows that most of the built-up land pixels were generated from the loss of the pixels of the other class (0.761). Most of the pixels of the vegetation class remained unchanged (0.179) while the rest was generated from transforming class other (0.826). The pixels of the water class have undergone an increase despite the transformation of the other class (0.619). The transition matrix from 2019 to 2039 shows that most of the pixels of the frame have remained unchanged (0.747), the surplus is mainly generated by the loss of pixels from the other class $(0.202)$ and pixels from the vegetation class $(0.051)$. The loss of part of the pixels of the other class is due to their transformation into the built-class pixel (0.051). 


\subsubsection{Influence of Potential Urban Growth on Various LULC}

A net rise of $1708 \mathrm{~km}^{2}$ in urban areas and an urban growth rate of 33.88 percent between 2019 and 2039 was demonstrated by the built-up expansion shown by the CA-based urban growth model (Table 5 and Figure 9). This will affect the other categories of LULC (net loss: $3.32 \mathrm{~km}^{2}$ ) and the coverage of the plant (loss: $1.3 \mathrm{~km}^{2}$ ). The research shows that, during the period 2019-2039, the urban growth rate in Benslimane will not be high.

Table 4. The statistical variability as per satellite-based and simulated photos of built-up land.

\begin{tabular}{lccc}
\hline \multirow{2}{*}{ Variables } & \multicolumn{3}{c}{ Built-up areas in $\mathbf{k m}^{\mathbf{2}}$} \\
\cline { 2 - 4 } & $\mathbf{1 9 9 9}$ & $\mathbf{2 0 0 9}$ & $\mathbf{2 0 1 9}$ \\
\hline $\begin{array}{l}\left.\text { Actual (Km }{ }^{2}\right) \\
\text { Simulated }\end{array}$ & 2,147 & 2,999 & 5,044 \\
$\begin{array}{l}\left.\mathbf{K}^{2}\right) \\
\text { Spatial } \\
\text { accuracy }\end{array}$ & 2,330 & 3,294 & 5,533 \\
\hline
\end{tabular}

\section{Conclusions}

The research covers the spatio-temporal monitoring of Benslimane's LULC (1989-2019) and urban growth modeling (1999-2039) to glean the past and future urban growth paradigm and its effect on the land use/coverage variety using the CA model. During the period 1989-2019, the simulated and satellite-based LULC satellite experienced rapid urban growth (net increase of 3,838 $\mathrm{km}^{2}$ and $4,327 \mathrm{~km}^{2}$ ), resulting in a land-use transition in Benslimane. The other groups were modified by population development $-17.4 \%$, followed by vegetation cover $(20.13 \%)$ and water level (1,62\% variation). The simulated LULC based on AC shows that the urban area will expand to 5,044 and 6,752 $\mathrm{km}^{2}$ in 2029 and 2039, respectively, mainly in the western and southwestern sections. In the period 2019-2039, urban development will replace and transform the "other" category of LULC (loss of $1.36 \mathrm{~km}^{2}$ ) and the category of vegetation cover (loss of $0.34 \mathrm{~km}^{2}$ ).

In the simulated and satellite LULC over the described years (1989-2019), the dynamics of transition were parallel. For the years 1999 and 2019, the study of the spatial variance performed using the PCA technique showed high construction precision. The overall accuracy of the confusion matrix (97.23\%) and of the area under the receiver operational characteristics (ROC) curve (0.94), measured using the satellite-built patch and simulated for 2019, underlines the high modeling accuracy. 
Figure 7. Cellular automata (CA) model-based simulated built-up growth for (a) 2029 and (b) 2039.
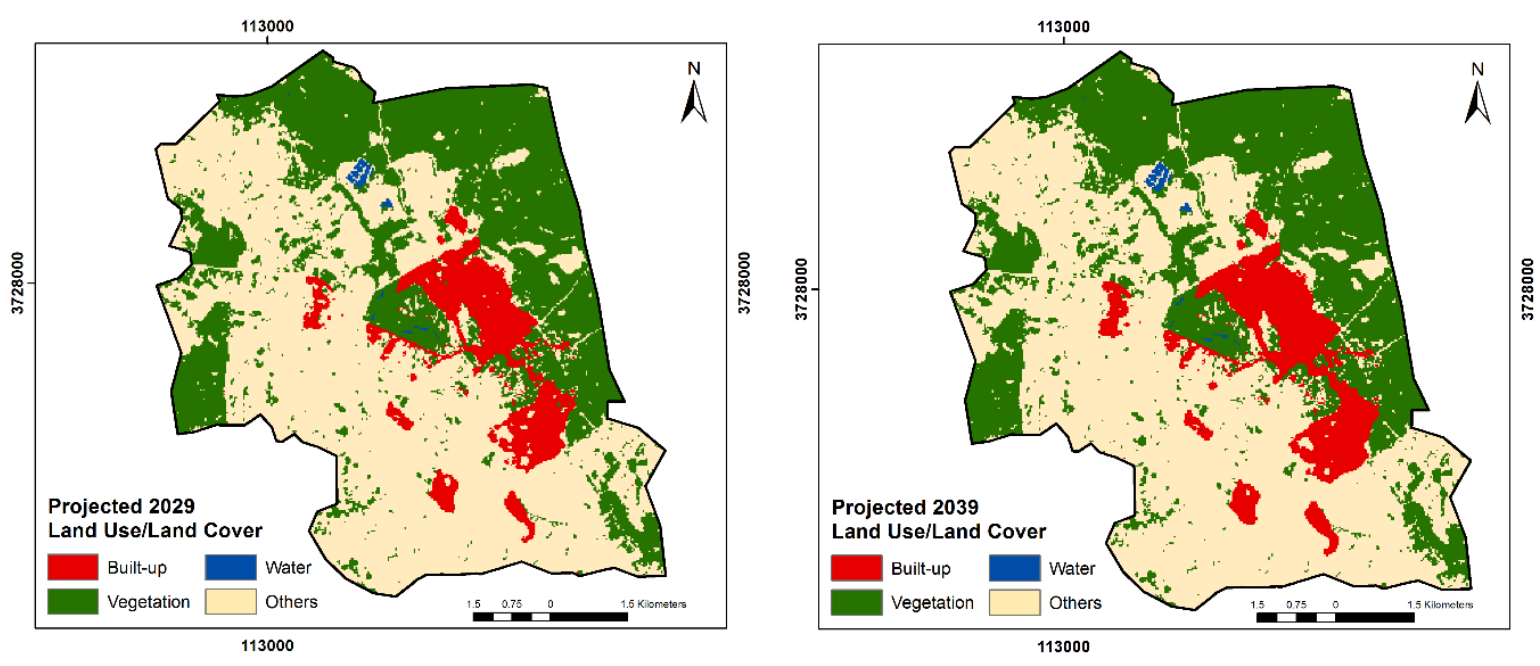

Figure 8. Receiver operating characteristic (ROC) curve for the actual and simulated built-up land during 2019.

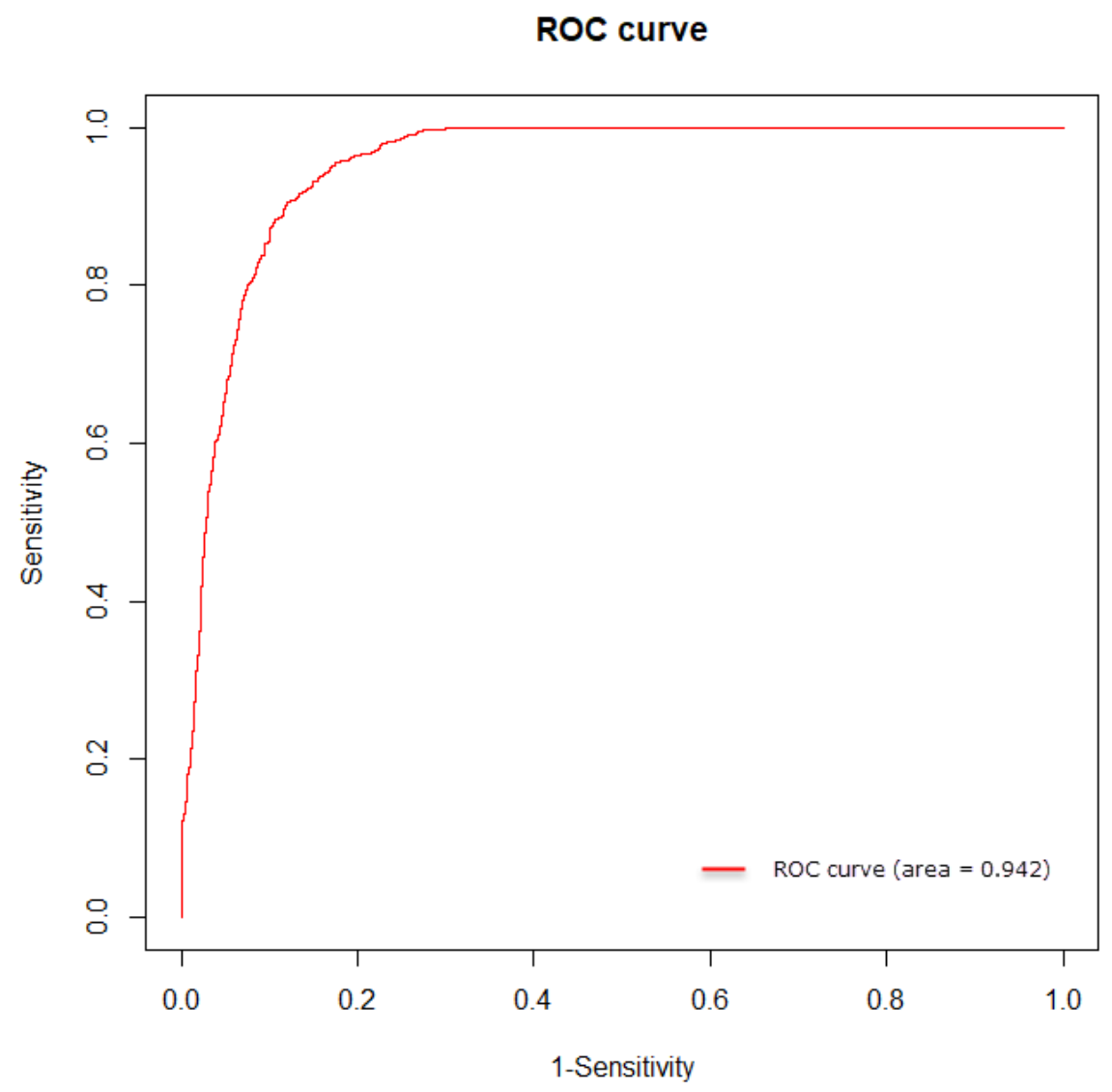


Table 5. Area statistics of varied classes for the year 2019 and projected 2029 and 2039 with the percentage change.

\begin{tabular}{lcrrc}
\hline & $2019\left(\mathrm{~km}^{2}\right)$ & $2029\left(\mathrm{~km}^{2}\right)$ & $2039\left(\mathrm{~km}^{2}\right)$ & \% Change 2019-2039 \\
\hline Built-up & 5.044 & 6.0921 & 6.7527 & 33.887 \\
Vegetation & 26.068 & 25.8894 & 25.7229 & -1.322 \\
Water & 0.202 & 0.2007 & 0.2007 & -0.446 \\
Others & 41.023 & 40.1535 & 39.6594 & -3.324 \\
\hline
\end{tabular}

An attempt was made to demonstrate the relationship between variables related to the phase of spreading over time (1999-2039), which highlighted the strong impact over time of proximity to built-up areas and the city center during the initial observation period, although the population density contribution increased later.

Table 6. Confusion matrix for actual and simulated 2019 built-up pixels.

\begin{tabular}{llllll}
\hline & & Predicted & & $\begin{array}{l}\text { Percentage } \\
\text { correct }\end{array}$ & $\begin{array}{c}\text { Overall } \\
\text { accuracy }\end{array}$ \\
\cline { 3 - 5 } & & Non-built-up & Built-up & & \\
\hline \multirow{2}{*}{ Actual } & Nonbuilt-up & 111491 & 3037 & $97.35 \%$ & \\
& Built-up & 224 & 3108 & $93.28 \%$ & $97.23 \%$ \\
\hline
\end{tabular}

Table 7. Transition matrix (satellite-based 1989 to 2019).

\begin{tabular}{lcccc}
\hline LULC & Built up & Vegetation & Water & Others \\
\hline Built up & 0,239 & 0 & 0 & 0,761 \\
Vegetation & 0 & 0,821 & 0 & 0,179 \\
Water & 0 & 0 & 0,381 & 0,619 \\
Others & 0,077 & 0,094 & 0,002 & 0,826 \\
\hline
\end{tabular}

Table 8. Transition matrix (satellite-based 2019 to 2039).

\begin{tabular}{lcccc}
\hline & Built up & Vegetation & Water & Others \\
\hline Built up & 0,747 & 0,051 & 0 & 0,202 \\
Vegetation & 0,013 & 0,987 & 0 & 0 \\
Water & 0,010 & 0 & 0,990 & 0 \\
Others & 0,033 & 0 & 0,000 & 0,967 \\
\hline
\end{tabular}

The calibrated CA model replicated the process of sprawl in the real world statistically, while the spatial analogy was mild. In the case of the town of Benslimane, where urban sprawl is often spontaneous and unforeseen, this high spatial accuracy shows the limits. To calibrate the model to forecast urban sprawl for years to come, this work centered on increasing the precision of the CA model and used data from four uniformly spaced expansion times. 


\section{Author Contributions:}

Conceptualization, M.B; Methodology, M.B, F.B, H.R; Software, M.B; H.R; S.B; T.B; validation, M.B, F.B, H.R .; formal analysis, M.B, F.B, H.R, S.B; T.B; N.B; M.B ;investigation, M.B; resources, M.B; H.R; data curation, F.B; H.R .N.B; M.B; preparation, M.B, F.B, H.R;

Funding: this research work has not received any funding

Conflicts of Interest: The authors declare no conflict of interest

\section{References}

1. He, C.; Tian, J.; Shi, P.; Hu, D. Simulation of the spatial stress due to urban expansion on the wetlands in Beijing, China using a GIS-based assessment model. Landsc. Urban Plan. 2011, 101, 269-277.

2. Jenerette, G.D.; Harlan, S.L.; Brazel, A.; Jones, N.; Larsen, L.; Stefanov, W.L. Regional relationships between surface temperature, vegetation, and human settlement in a rapidly urbanizing ecosystem. Landsc. Ecol. 2007, 22, $353-365$.

3. Seto, K.C. Exploring the dynamics of migration to mega-delta cities in Asia and Africa: Contemporary drivers and future scenarios. Glob. Environ. Change 2011, 21, S94-S107.

4. Hersperger, A.M.; Oliveira, E.; Pagliarin, S.; Palka, G.; Verburg, P.; Bolliger, J.; Grădinaru, S. Urban land-use change: The role of strategic spatial planning. Glob. Environ. Change 2018, 51, 32-42.

5. Saadani, S.; Laajaj, R.; Maanan, M.; Rhinane, H.; Aaroud, A. Simulating spatial-temporal urban growth of a Moroccan metropolitan using CA-Markov model. Spat. Inf. Res. 2020, 28, 609-621, doi:10.1007/s41324-020-00322-0.

6. Poelmans, L.; Van Rompaey, A. Complexity and performance of urban expansion models. Comput. Environ. Urban Syst. 2010, 34, 17-27.

7. Arsanjani, J.J.; Helbich, M.; Kainz, W.; Boloorani, A.D. Integration of logistic regression, Markov chain and cellular automata models to simulate urban expansion. Int. J. Appl. Earth Obs. Geoinformation 2013, 21, 265-275.

8. Aburas, M.M.; Ho, Y.M.; Ramli, M.F.; Ash'aari, Z.H. The simulation and prediction of spatio-temporal urban growth trends using cellular automata models: A review. Int. J. Appl. Earth Obs. Geoinformation 2016, 52, 380-389.

9. Musa, S.I.; Hashim, M.; Reba, M.N.M. A review of geospatial-based urban growth models and modelling initiatives. Geocarto Int. 2017, 32, 813-833.

10. Batty, M.; Xie, Y.; Sun, Z. Modeling urban dynamics through GIS-based cellular automata. Comput. Environ. Urban Syst. 1999, 23, 205-233.

11. Michalak, W.Z. GIS in land use change analysis: integration of remotely sensed data into GIS. Appl. Geogr. 1993, $13,28-44$.

12. Liao, F.H.; Wei, Y.D. Modeling determinants of urban growth in Dongguan, China: a spatial logistic approach. Stoch. Environ. Res. Risk Assess. 2014, 28, 801-816.

13. Hu, Z.; Lo, C.P. Modeling urban growth in Atlanta using logistic regression. Comput. Environ. Urban Syst. 2007, 31 , $667-688$.

14. Mom, K.; Ongsomwang, S. URBAN GROWTH MODELING OF PHNOM PENH, CAMBODIA USING SA TELLITE IMAGERIES AND A LOGISTIC REGRESSION MODEL. Suranaree J. Sci. Technol. 2016, 23.

15. Tahami, H.; Basiri, A.; Moore, T.; Park, J.; Bonenberg, L. Virtual spatial diversity antenna for GNSS based Mobile positioning in the harsh environments. In Proceedings of the Proceedings of the 31st International Technical Meeting of the Satellite Division of The Institute of Navigation (ION GNSS+ 2018); 2018; pp. 3186-3198. 
16. Tayyebi, A.; Pijanowski, B.C. Modeling multiple land use changes using ANN, CART and MARS: Comparing tradeoffs in goodness of fit and explanatory power of data mining tools. Int. J. Appl. Earth Obs. Geoinformation 2014, 28, 102-116.

17. Pijanowski, B.C.; Brown, D.G.; Shellito, B.A.; Manik, G.A. Using neural networks and GIS to forecast land use changes: a land transformation model. Comput. Environ. Urban Syst. 2002, 26, 553-575.

18. Mohammady, S.; Delavar, M.R. Urban sprawl assessment and modeling using landsat images and GIS. Model. Earth Syst. Environ. 2016, 2, 155.

19. Pijanowski, B.C.; Gage, S.H.; Long, D.T.; Cooper, W.C. A land transformation model: integrating policy, socioeconomics and environmental drivers using a geographic information system. Landsc. Ecol. Top Approach 2000, 183-198.

20. Tayyebi, A.; Pijanowski, B.C.; Tayyebi, A.H. An urban growth boundary model using neural networks, GIS and radial parameterization: An application to Tehran, Iran. Landsc. Urban Plan. 2011, 100, 35-44.

21. Pourebrahim, N.; Sultana, S.; Thill, J.-C.; Mohanty, S. Enhancing trip distribution prediction with twitter data: comparison of neural network and gravity models. In Proceedings of the Proceedings of the 2nd ACM SIGSPATIAL International Workshop on AI for Geographic Knowledge Discovery; 2018; pp. 5-8.

22. Tian, G.; Ma, B.; Xu, X.; Liu, X.; Xu, L.; Liu, X.; Xiao, L.; Kong, L. Simulation of urban expansion and encroachment using cellular automata and multi-agent system model—A case study of Tianjin metropolitan region, China. Ecol. Indic. 2016, 70, 439-450.

23. Hosseinali, F.; Alesheikh, A.A.; Nourian, F. Agent-based modeling of urban land-use development, case study: Simulating future scenarios of Qazvin city. Cities 2013, 31, 105-113.

24. Babakan, A.S.; Taleai, M. Impacts of transport development on residence choice of renter households: An agent-based evaluation. Habitat Int. 2015, 49, 275-285.

25. Li, X.; Yeh, A.G.-O. Neural-network-based cellular automata for simulating multiple land use changes using GIS. Int. J. Geogr. Inf. Sci. 2002, 16, 323-343.

26. Shi, W.; Pang, M.Y.C. Development of Voronoi-based cellular automata-an integrated dynamic model for Geographical Information Systems. Int. J. Geogr. Inf. Sci. 2000, 14, 455-474.

27. He, C.; Okada, N.; Zhang, Q.; Shi, P.; Zhang, J. Modeling urban expansion scenarios by coupling cellular automata model and system dynamic model in Beijing, China. Appl. Geogr. 2006, 26, 323-345.

28. Zhang, Y.; Li, X.; Liu, X.; Qiao, J. The CA model based on data assimilation. J. Remote Sens. 2011, 15, 475-491.

29. Wu, F.; Martin, D. Urban expansion simulation of Southeast England using population surface modelling and cellular automata. Environ. Plan. A 2002, 34, 1855-1876.

30. Tobler, W.R. A computer movie simulating urban growth in the Detroit region. Econ. Geogr. 1970, 46, $234-240$.

31. Clarke, K.C.; Hoppen, S.; Gaydos, L. A self-modifying cellular automaton model of historical urbanization in the San Francisco Bay area. Environ. Plan. B Plan. Des. 1997, 24, 247-261.

32. Batty, M.; Xie, Y. From cells to cities. Environ. Plan. B Plan. Des. 1994, 21, S31-S48.

33. Wu, F. Calibration of stochastic cellular automata: the application to rural-urban land conversions. Int. J. Geogr. Inf. Sci. 2002, 16, 795-818.

34. He, C.; Shi, P.; Chen, J.; Li, X.; Pan, Y.; Li, J.; Li, Y.; Li, J. Developing land use scenario dynamics model by the integration of system dynamics model and cellular automata model. Sci. China Ser. Earth Sci. 2005, 48, 1979-1989.

35. Li, X.; Gar-On Yeh, A. Data mining of cellular automata's transition rules. Int. J. Geogr. Inf. Sci. 2004, 18, 723-744.

36. Li, D.; Li, X.; Liu, X.; Chen, Y.; Li, S.; Liu, K.; Qiao, J.; Zheng, Y.; Zhang, Y.; Lao, C. GPU-CA model for large-scale land-use change simulation. Chin. Sci. Bull. 2012, 57, 2442-2452.

37. Mustafa, A.; Cools, M.; Saadi, I.; Teller, J. Coupling agent-based, cellular automata and logistic regression into a hybrid urban expansion model (HUEM). Land Use Policy 2017, 69, 529-540. 
38. Zhang, Y.; Liu, X.; Chen, G.; Hu, G. Simulation of urban expansion based on cellular automata and maximum entropy model. Sci. China Earth Sci. 2020, 1-12.

39. Liu, X.; Ma, L.; Li, X.; Ai, B.; Li, S.; He, Z. Simulating urban growth by integrating landscape expansion index (LEI) and cellular automata. Int. J. Geogr. Inf. Sci. 2014, 28, 148-163.

40. Chaudhuri, G.; Clarke, K. The SLEUTH Land Use Change Model: A Review. Environ. Resour. Res. 2013, 1, 88-105, doi:10.22069/ijerr.2013.1688.

41. Benchelha, M.; Benzha, F.; Rhinane, H. OBJECT BASED "DAYAS “ CLASSIFICATION USING SENTINEL A-2 SATELLITE IMAGERY CASE STUDY CITY OF BENSLIMANE. 2019, 7.

42. Kumar, U.; Mukhopadhyay, C.; Ramachandra, T.V.; Infrastructure, S.T.; Planning, U. Cellular automata and Genetic Algorithms based urban growth visualization for appropriate land use policies. In Proceedings of the The Fourth Annual International Conference on Public Policy and Management, Centre for Public Policy, Indian Institute of Management (IIMB); 2009.

43. Tripathy, P. Monitoring and modelling spatio-temporal urban growth of Delhi using Cellular Automata and geoinformatics. 2019, 12. 